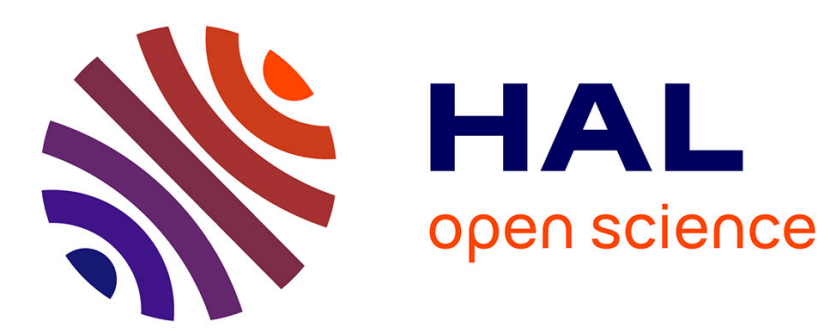

\title{
Model Systems of Human Intestinal Flora, to Set Acceptable Daily Intakes of Antimicrobial Residues
}

Denis E. Corpet

\section{To cite this version:}

Denis E. Corpet. Model Systems of Human Intestinal Flora, to Set Acceptable Daily Intakes of Antimicrobial Residues. Microbial Ecology in Health and Disease, 2000, 12 (Suppl 1), pp.37-41. hal-00552152

\section{HAL Id: hal-00552152 \\ https://hal.science/hal-00552152}

Submitted on 5 Jan 2011

HAL is a multi-disciplinary open access archive for the deposit and dissemination of scientific research documents, whether they are published or not. The documents may come from teaching and research institutions in France or abroad, or from public or private research centers.
L'archive ouverte pluridisciplinaire HAL, est destinée au dépôt et à la diffusion de documents scientifiques de niveau recherche, publiés ou non, émanant des établissements d'enseignement et de recherche français ou étrangers, des laboratoires publics ou privés. 
Microbial Ecology in Health and Disease, 12, Suppl 1, 37-41. Author's Version

\title{
Model Systems of Human Intestinal Flora, to Set Acceptable Daily Intakes of Antimicrobial Residues
}

\author{
Denis E. Corpet \\ Sécurité des Aliments, Institut National Recherche Agronomique, \\ Ecole Nationale Vétérinaire, 23 ch. Capelles, 31076 Toulouse, France
}

\begin{abstract}
The veterinary use of antimicrobial drugs in food producing animals may result in residues in food, that might modify the consumer gut flora. This review compares three model systems that maintain a complex flora of human origin: (i) human flora associated (HFA) continuous flow cultures in chemostats, (ii) HFA mice, and (iii) human volunteers. The "No Microbial Effect Level" of an antibiotic on human flora, measured in one of these models, is used to set the acceptable daily intake (ADI) for human consumers. Human volunteers trials are most relevant to set microbiological ADI, and may be considered as the "gold standard". However, human trials are very expensive and unethical. HFA chemostats are controlled systems, but tetracycline ADI calculated from a chemostat study is far above result of a human study. HFA mice studies are less expensive and better controlled than human trials. The tetracycline ADI derived from HFA mice studies is close to the ADI directly obtained in human volunteers.
\end{abstract}

\section{Introduction}

The veterinary use of antimicrobial drugs in food producing animals may result in antibiotic residues in food. The intake of meat, milk or eggs containing low levels of antibiotic might modify the intestinal microflora of the consumer. Of particular concern is the selection of drug resistant bacteria in the gut. The microbiological safety of these residues is not easy to assess, and many experimental models had been proposed and reviewed $(1,2)$. The present paper gives a short overview of in vivo model systems, and compare three model systems that maintain a complex flora of human origin: (i) human flora associated (HFA) continuous flow cultures in chemostats, (ii) HFA mice, and (iii) human volunteers. The aim of these models is to find the no microbial effect level (NoMEL) of an antibiotic on human flora. This NoMEL value is extrapolated to set the acceptable daily intake (ADI) that will not produce an adverse effect on the gut flora of a human consumer. This paper discusses how ADI can be derived from NoMEL, and the pros and cons of the three models.

\section{Microbiological Adverse Effect:}

How may drug residues be harmful to the human intestinal microflora?

Gut flora maintains a "barrier" that prevents colonization by, and overgrowth of, unwanted bacteria, e.g., drug resistant or pathogenic strains.

- Drug resistance. Antibiotic residues might favor the growth of antibiotic resistant bacteria in the gut. The reservoir of resistant genes would thus enlarge, increasing the probability that a resistance gene is transferred to a pathogen.

- Pathogens. Antibiotic residues might reduce the colonization resistance to pathogenic invaders (Salmonella sp., Clostridium difficile, Campylobacter sp., Entero-Pathogenic E. coli, Staphylococcus aureus, Candida sp.). The overgrowth of these pathogens could lead to diarrhea or enterocolitis. Salmonella may be more a public health problem than Clostridia, which are often found in hospitalized patients, because of antibiotic therapy.

- Other changes. Antibiotics may change some bacterial density and/or some bacterial enzymatic activity in the gut, with no known clinical consequence. Drug residues may even induce beneficial changes in the gut; e.g., neomycin can decrease the intestinal concentration of toxic secondary bile acids (3).

Antibiotic resistance and pathogen overgrowth are probably the only true adverse effects for humans, and thus the only relevant endpoints to be assessed when testing the effects of a residue on intestinal microflora. In addition, the proportion of drug resistant bacteria in vivo may be the most sensitive endpoint in most studies (4). 
In vivo model systems: humans, conventional animals, and HFA mice

- Human volunteers: Since the inter-subject and dayto-day variability of the flora is high in humans, trials should be randomized, placebo-controlled and double-blinded, and should include at least 20 volunteers per group, treated for more than 20 days (1). Each group should be dosed with either (i) a placebo, (ii) the tested drug (at leat, two dose levels), and (iii) a drug known to change the flora, e.g., clindamycin at a dose of $0.6 \mathrm{~g} /$ day (positive control) (5). The intestinal microflora should be monitored daily, and compliance assessed by assaying the drug in urine or stools.

- Conventional animal models: The composition of animals' flora is far from the humans'. Rodents have no $E$. coli. Farm animals often have flora with a high resistance baseline to antibiotics. Monkeys are very expensive and therefore their use as a routine model system is not recommended. The flora of dogs is different from that of humans, but dog may be an acceptable species for this purpose (6).

- HFA mice: Groups of germ-free mice maintained in complete bacteriological isolation in isolators, are inoculated by gavage with an anaerobic dilution of human stools $(1,7)$. These HFA mice retain a high number of dominant anaerobes from the human gut flora. This complex flora can thus resist colonization by sub-dominant aerobes, drug-resistant and pathogenic strains $(7,8)$.

\section{HFA mice and men:}

\section{How should we extrapolate from a NoMEL to an ADI?}

HFA mice studies can be used to find the oral dose with no adverse effect on microbiological parameters (in vivo NoMEL). To translate the NoMEL to an ADI in humans, three different approaches can be used. The simplest is to consider that the same drug concentration in total intake, diet and water, will produce the same effect in the gut. A second simple method is to translate the daily intake per $\mathrm{kg}$ of metabolic body weight (i.e., BW to the power 0.72). These two simpleminded approaches lead to similar values when mouse data are extrapolated to humans (1). A third and more sophisticated approach requires extra experimental data. Let us assume that the bacteria have the same reaction to the drug in vivo, independent of the host (i.e., human or mouse). Therefore, the No Microbial Effect Concentration (NoMEC) should be identical inside the gut of mice and men. To extrapolate from mice to humans, the "dilution factor" between the mouth and the large bowel must be measured in both species. The Mouse Cecal Concentration (MCC) resulting from a given Mouse Intake (MI) and the Human Fecal Concentration (HFC) resulting from a given Human Intake (HI) should be measured.

In mice, NoMEC $(\mu g / g)=$ NoMEL $(g / k g B W) \times$ $\operatorname{MCC}(\mu g / g) / \mathrm{MI}(g / \mathrm{kg} \mathrm{BW})$

In men, NoMEC $(\mu g / g)=$ ADI $(g / k g B W) \times$ HFC $(\mu g / g) / \mathrm{HI}(g / \mathrm{kg} \mathrm{BW})$

Because human NoMEC $=$ mouse NoMEC ADI $x$ HFC $/ \mathrm{HI}=$ NoMEL $\times$ MCC $/ \mathrm{MI}$ ADI $=$ NoMEL $\times$ MCC/MI $\times$ HI/HFC If the human "dilution factor" could not be measured in volunteers, it should be estimated. The fecal concentration of a non-absorbed agent equals the daily intake divided by the daily fecal weight. Absorption and metabolism must be accounted for by estimated percentages. The human dilution factor might thus be estimated by the following formula:

$\mathrm{HFC} / \mathrm{HI}=\%$ Unabsorbed $\mathrm{x} \%$ Unchanged $\mathrm{x} 60(\mathrm{~kg}$ $B W) / 0.15$ ( $k g$ feces)

I think that there is no need to add a safety factor, because (i) the effect is not a true disease, (ii) it is measured in the target species (human bacteria), and (iii) the model system is very sensitive. Other authors think that a safety factor must be included in the calculation, to account for inter-individual variability.

\section{Advantages of HFA mice over humans and chemostats}

- Why are HFA mice studies better than human studies?

A mouse study is less expensive than a human trial. Mice are easy to handle, and their flora is "normalized" at the start of the study (all mice are dosed with the same flora). No contamination or cross-contamination occurs during the trial (bacteria or drug do not cross the isolator). Mice may be dosed with drugs not allowed for human use, or challenged with pathogenic bacteria. In addition, mice's food composition is stable. A study with human volunteers is more difficult to control and can be unethical.

Day-to-day variations in resistance levels are observed in HFA mice, but are smaller than in humans (7). A low baseline of resistant organisms can be obtained by selecting human donors. These features make HFA mice a better controlled system than human volunteers (Table 1). When comparing the sensitivity of HFA mice and humans to the effect of low doses of tetracycline or ampicilline (7) on the proportion of drug resistant E.coli, it is concluded 
that the mouse model may be slightly more sensitive than the human model (Table 2).

\section{- Why are HFA mice studies better than chemostats studies?}

Mice are easier to handle than chemostats (they self-regulate temperature, $\mathrm{pH}$, nutrients). One mouse is less expensive than one chemostat, accordingly, 20 to 30 "experimental units" may be handled simultaneously. Therefore, in contrast with chemostat study, the sample size in HFA mice study is larger than one. However, data independence is not perfect since cross-contamination may occur within a cage and/or within an isolator, but not between isolators. The same kind of contamination can also occur in chemostats, and we do not know data showing that the composition of the flora remains the same after its transfer from the human gut to a chemostat.

Mice are live animals and provide a natural environment to the bacteria. This environment supports the growth of "fastidious" bacteria, e.g., Clostridium difficile, which is not always the case with chemostats (3). The mouse model also provides (i) day-to-day variations in drug and nutrients levels in the gut ("feast and famine cycles"), (ii) ecological niches, i.e., colonic crypts and particles like fibers or cells from the mucosa (iii) semi-solid stools and a large mucosal surface for adhesion, which is a major determinant of the dynamic of resistance plasmid that is not reproduced in chemostats $(9,10,11)$, and (iv) a gradient of endogenous nutrients like mucins, shed cells, bile acids, fibers, and metabolites. These features make the HFA mouse a more relevant model than the chemostat (Table 3). Moreover, the chemostat model appears to be much less sensitive to tetracycline effect than the human model (Table 2).

\section{Advantages of humans and chemostats over HFA mice}

- Why are human studies better than HFA mice studies?

Humans harbor human flora. Some human bacteria may disappear when the human flora is transferred into the mouse intestine (e.g., lactobacilli, bifidobacteria) (12). The ecology of the colonic flora may be different in mice and humans, because of the smaller volume and areas. There are also chemical differences in proteins, mucins, blood groups, bile acids, and other endogenous compounds between mice and humans. reflect the variability of human flora. This 39 variability does not exist when the HFA mice are given the same (pool of) human flora(s). Volunteers leave a real life situation, which means many bacterial contaminations (13). In people, a drug treatment may boost new plasmids that enter the gut at random. However, HFA mice could also be given bacterial contaminants, like plasmid-bearing strains or pathogen challenges.

The fate of drugs may not be the same in mice and men: absorption, excretion in the bile, change from the parent drug to inactive metabolites. Some differences could be accounted for by measuring the true "dilution factor" in both mice and men (see above). However, in the human model, the NoMEL in humans can directly be used as an ADI with no extrapolation needed. These human trials features make them the "gold standard" (Table 1).

\section{- Why are chemostats studies better than HFA mice studies?}

Today, more laboratories can handle a chemostat than germ-free mice (a chemostat is less expensive to set up than a germ-free facility, it requires less room, and technology is easier to learn). Each mouse fecal pellet is large enough for microbial counts. However, biochemical assays require large samples, obtained by pooling fecal samples from several mice, which reduces statistical power.

Sequential chemostat studies may give identical results, provided the same "starter" flora is used and kept deep-frozen. The same frozen "starter" can also be used to inoculate germ-free mice, although this has not yet been done. However, when different floras are used to inoculate a chemostat, different results are obtained, like in HFA mice studies (14).

HFA mice studies sometimes yield discrepant or inconsistent results. For example, a drug can show an effect in male but not in female mice. The source of these discrepancies is not known, but may reflect the variability of the biological response. Mice may fight badly (notably male mice), escape from the cage and make a hole in the isolator, die, or be constipated. These problems do not exist in chemostats; thus they are better controlled systems than HFA mice (Table $3)$. 


\section{Conclusions:}

Human volunteers trials are clearly the most relevant studies to set microbio logical ADI: Data may be used directly and they may be considered as the "gold standard" $(7,15)$. However, they human trials are very expensive and unethical. Thus, regulation agencies and industrial firms need other models of human intestinal microflora to assess the effect of antimicrobial residues. Chemostats with the continuous flow culture of a human flora are controlled systems, where the effect of antibiotic can easily be tested. The complex microflora stabilizes in the chemostat, and large samples may be taken for biochemical analysis. However, chemostats lack many features of living systems, and ADI calculated from chemostats studies are far from human studies results, at least for tetracycline. HFA mice trials are less expensive and more ethical to use, and can be better controlled than human trials. Compared with chemostats they provide true living ecological environment to the gut flora. Finally, the tetracycline ADI derived from HFA mice studies $(7,12)$ is close to the ADI directly obtained in human volunteers (15).

\section{REFERENCES}

1. Corpet DE. (1993) Current status of models for testing antibiotic residues. Vet Human Toxicol. 35: 37-46.

2. Cerniglia CE, Kotarski S. (1999) Evaluation of veterinary drug residues in food for their potential to affect human intestinal microflora. Regulatory Toxicology and Pharmacology. 29: 238-261.

3. Carman RJ. (1999) Continuous flow one chamber chemostat: effect of selected antimicrobials on the human intestinal microflora. Microbiological safety of drug residues in food. FDA-CVM. Rockville, MD.

4. Bartholomew MJ. (1999). Panel discussion 1, Microbiological endpoints and public health concern. Microbiological safety of drug residues in food. FDA-CVM. Rockville, MD.

5. Vollaard EJ, Clasener HAL, Janssen AJHM. (1990) The contribution of Escherichia coli to microbial colonization resistance. J Antimicr Chemother. 26: 411-418.

6. Rollins LD, Gaines SA, Pocurull DW, Mercer HD. (1975) Animal model for determining the no-effect level of an antimicrobial drug on drug resistance in the lactose-fermenting enteric flora. Antimicrob Agents Chemother. 7: 661-665.

7. Corpet DE. (1987) Antibiotic residues and drug resistance in human intestinal flora. Antimicr Agents Chemother. 31: 587-593.

8. Wong WC, Hentges DJ, Dougherty SH. (1996) Adequacy of the human faecal microbiota associated mouse as a model for studying the ecology of the human intestinal tract. Microbial Ecology in Health and Disease. 9: 187-198.

9. Freter R, Freter RR, Brickner H. (1983) Experimental and mathematical models of Escherichia coli plasmid transfer in vitro and in vivo. Infect Immun. 39: 60-84.

10. Corpet DE, Lumeau S. (1987) Antibiotic residues and R-plasmid selection : are in vitro methods good models ? Zbl Bakt Hyg. 264 A: 178-184.

11. Licht TR, Christensen BB, Krogfelt KA, Molin S. (1999) Plasmid transfer in the animal intestine and other dynamic bacterial populations: the role of community structure and environment. Microbiology - UK. 145: 2615-2622.

12. Guyomard, A. (1999) Human flora associated (HFA) mice: effect of selected antimicrobials on the human intestinal flora. Microbiological safety of drug residues in food. FDA-CVM. Rockville, MD.

13. Corpet DE. (1988) Antibiotic resistance from food. New Engl J Med. 318: 1206-1207.

14. Kotarski SF. (1999) Variability encountered in model systems designed to test antimicrobial effects on the intestinal microflora. Microbiological safety of drug residues in food. FDA-CVM. Rockville, MD.

15. Tancrede C, Barakat R. (1989) Ecological impact of low doses of oxytetracycline on human intestinal microflora. J Vet Med. 42: 35-39. 
Table 1: Respective benefits of HFA mice and human volunteers to assess the effect of antimicrobial residues on human gut flora.

\section{HFA mice benefits}

- less expensive

- easier to handle

- one flora, many mice

- no contamination

- controlled diet

- smaller variability

- low baseline resistance

$\Rightarrow$ sensitive system

- any drug

- pathogen challenge

=> More ethical

Better Controlled
Human volunteers benefits

- true human flora

- large human gut

- individual variability

- real contaminations ${ }^{\text {a }}$

- real diet (variable) ${ }^{\mathrm{b}}$

- human bile, mucus...

- true human drug metabolism ${ }^{\mathrm{c}}$

- no calculation or extrapolation is needed to set ADI

"Gold standard"

\section{Notes to Table 1.}

a- The HFA mice model can be improved by introducing on purpose plasmid bearing strains in the isolator, to mimic human contaminations.

b- The HFA mice model can be improved by feeding mice with various human foods.

c- Data from the HFA mice model should be corrected with measured "dilution factor" (see text).

Table 2. Comparison of Acceptable Daily Intake (ADI) for human beings, extrapolated from three experimental models: chemostat, HFA mice and human volunteers. Results show the lowest tetracycline level that increases tetracycline resistance in the human gut flora.

\begin{tabular}{|c|c|c|c|c|}
\hline Reference & Model & $\begin{array}{l}\text { Lowest tested level } \\
\text { with an effect }^{\mathrm{a}}\end{array}$ & & $\begin{array}{l}D I^{b} \\
g / d\end{array}$ \\
\hline Carman (3) & chemostat & $15 \mu \mathrm{g} / \mathrm{ml}$ medium & $<$ & $150 .^{\mathrm{c}}$ \\
\hline Corpet (7) & HFA mice & $0.5 \mathrm{ppm}$ in water & $<$ & $0.75^{\mathrm{d}}$ \\
\hline Guyomard (12) & HFA mice & $1 \mathrm{ppm}$ in water & $<$ & $1.5^{\mathrm{d}}$ \\
\hline Tancrede (15) & volunteers & $2 \mathrm{mg} /$ person $/ \mathrm{d}^{\mathrm{e}}$ & $<$ & 2.0 \\
\hline
\end{tabular}

Notes to Table 2:

a- Minimum tetracycline dose leading to significant increase in the proportion of drug-resistant $E$. coli in the human gut flora. In HFA mice and humans, the no effect level was not determined. In the chemostat study, 1.5 $\mu \mathrm{g} / \mathrm{ml}$ was a no effect level.

b- Maximum extrapolated ADI for a person of $60 \mathrm{~kg} \mathrm{BW}$. Derived only for comparisons, and should not be used as such for regulations.

c- $15 \mu \mathrm{g} / \mathrm{d}$ matches 100 "FDA-ADI", that is 100 times $1.5 \mathrm{mg} /$ person/d (3).

d- Extrapolation was done according to Cerniglia and Kotarsky (2). Calculations with different methods give similar results: ADIs derived from HFA mice studies are in the range $0.5-2 \mathrm{mg} /$ person/d $(1,7)$.

e- Tancrede's data (15) show that the proportion of resistant E.coli increased in each of the six volunteers given 2 $\mathrm{mg} / \mathrm{d}$ oxytetracycline for seven days, compared with control period (median increase: 30 times, range: 2-3200). In contrast with Tancrede's conclusion, this increase was significant at $\mathrm{p}=0.05$ (1) 
Table 3: Respective benefits of HFA mice and chemostat to assess the effect of antimicrobial residues on human gut flora.

\section{HFA Mice Benefits}

- easier to handle

- less expensive: many mice

- live animals :

$>$ mucus, bile, cells

$>$ drug variations

$>$ crypts, niches

- male and female

- results closer to humans' ${ }^{10}$
Chemostat Benefits

- more labs can do it

- better controlled

- larger samples ${ }^{\mathrm{a}}$

- always same starter flora ${ }^{\mathrm{b}}$

- less experimental incidents

- more ethical

\section{More Relevant}

\section{Better Controlled}

\section{Notes to Table 3.}

a- Large samples for biochemistry could be obtained from HFA mice, by pooling fecal samples, or taking cecal samples after sacrifice. An alternative might be the use of HFA rats.

b- A frozen "starter" flora could be used to inoculate germfree mice, exactly as done in chemostats. It would "normalize" the flora, but the barrier effect was weaker with a frozen flora than with a fresh flora (unpublished results, Corpet 92).

c- See Table 2. 